\title{
Grape pomace as a promising source of biologically valuable components
}

\author{
Anastasia Tikhonova*, Natalia Ageeva, and Ekaterina Globa
}

Federal State Budget Scientific Institution «North Caucasian Federal Scientific Center of Horticulture, Viticulture, Wine-making», 39 str. 40 Let Pobedy, Krasnodar, 350901, Russia

\begin{abstract}
Experimental data on the content of biologically valuable components in grape pomace are presented. The presence of organic acids was revealed in an amount from $33.35 \mathrm{~g} / \mathrm{kg}$ (Saperavi) to $108.2 \mathrm{~g} / \mathrm{kg}$ (Rebo). The main acid is tartaric. Phenolic compounds have been identified: anthocyanins, flavones, flavan-3-ols, oxycinnamic and hydroxybenzoic acids, procyanidins. The main anthocyanins found in grape pomace are the 3-O-glycosides of malvidin, petunidin, cyanidin, peonidin and delphinidin. The highest total content of hydroxybenzoic acids was in the pomace of Pinot Noir grapes $-720 \mathrm{mg} / \mathrm{kg}$, further in descending order of concentration followed by pomace from Saperavi grapes $(708 \mathrm{mg} / \mathrm{kg})$, Cabernet Sauvignon $(681 \mathrm{mg} / \mathrm{kg})$, Merlot $(575$ $\mathrm{mg} / \mathrm{kg}$ ) and Rebo $(545 \mathrm{mg} / \mathrm{kg})$. The highest total content of vitamins was found in the pomace of Rebo grapes $-639 \mathrm{mg} / \mathrm{kg}$, the lowest - Merlot $(471 \mathrm{mg} / \mathrm{kg})$. In all samples, vitamin B1 prevails, then in decreasing order - ascorbic acid, vitamins B2, B3, B5, B7. Moreover, their concentrations vary significantly depending on the grape variety from which the pomace is obtained. The influence of the grape variety on the content of these biologically valuable components in the pomace has been established, which must be taken into account in the production of biologically active substances that increase the nutritional status of a person.
\end{abstract}

\section{Introduction}

The program for the development of viticulture provides an increase of the area under grapes, including the technical varieties of grape intended for the production of wine. The number of wineries and peasant farms producing wine products is increasing. This leads to a significant increase in the amount of waste generated, most of which (up to 20-22\%) are grape pomace, which must be brought into circulation or disposure, since non-compliance with environmental protection requirements when handling production and consumption waste leads to violation of the Code of Administrative Offenses of the Russian Federation Article 8.2 and entails the imposition of fines. The use of grape pomace as a secondary raw material for the production of various types of products (polyphenol concentrates, tartaric acid, yeast casings, etc.) will increase the yield of finished products per unit of processed

\footnotetext{
${ }^{*}$ Corresponding author: Anastasia.he@yandex.ru
} 
raw materials, implementation of deep processing of grapes, reduce environmental pressure on the environment [1-3].

Grape pomace contains a significant amount of biologically valuable components, including natural bioflavonoids, trace elements, vitamins and vitamin-like compounds [46]. These components of grape pomace in domestic and foreign practice are effectively used as food additives, in the production of pharmaceuticals, cosmetics, animal food, fertilizers [7-9]. However, the content of biologically valuable components in the pomace of grapes varies and largely depends on a number of factors, including the grape variety, its place of growth and processing methods. This feature must be taken into account when developing new technologies for processing secondary raw materials in the wine industry, including pomace, aimed at minimizing industrial waste.

In this regard, the purpose of the work was to obtain new information on the physicochemical properties and chemical composition of high-molecular compounds of grape pomace, depending on the grape variety.

\section{Materials and methods}

Fermented red pomace of grape varieties - Saperavi, Cabernet Sauvignon, Merlot, Pinot Noir, Rebo were used as objects of research. The pomace was obtained in 2020 during the production of red table wine materials that reached the required color characteristics. To separate the pomace from the wine material, membrane drum pneumatic presses from various manufacturers were used.

The moisture content of the pomace was calculated as a percentage by weighing a sample before and after drying. Drying was carried out in a drying oven at a temperature of $100^{\circ} \mathrm{C}$ to constant weight.

Studies of mass concentrations of organic acids, cations of alkali and alkaline-earth metals were carried out on the basis of the scientific center "Winemaking" of the Federal State Budget Scientific Institution NCFSCHVW using highly efficient capillary electrophoresis on the device "Kapel 105" [10]. Extraction was carried out with hot water $\left(65-70^{\circ} \mathrm{C}\right)$ at a hydromodule of 1:5.

The mass concentrations of the components of phenolic compounds (including vitamins and vitamin-like substances) were determined in extracts by high performance chromatography using an Agilent Technologies chromatographic system (model 1100) with a diode array detector. A water-alcohol mixture with a strength of $50 \mathrm{vol} . \%$ Was used as an extractant. at hydromodule 1:5.

All tests were carried out with three repetitions.

\section{Results and discussion}

Table 1 presents the results of measuring the moisture content in the studied samples of grape pomace. As shown earlier [11], the moisture content of the pomace depends on the grape variety, the technology of its processing, first of all, the operating mode of the pressing equipment and the type of wine in the production of which they are obtained. The research results showed a variation in the moisture content of the pomace in a fairly wide range - from 48.5 to $64.5 \%$. 
Table 1. Moisture of the studied pomace of grapes

\begin{tabular}{|c|l|l|c|c|}
\hline № & \multicolumn{1}{|c|}{ Grapes variety } & \multicolumn{1}{c|}{ Growing area } & Press firm & Moisture, \% \\
\hline 1 & Pinot Noir & Temryukskiy & «Busher Vaslin» (France) & $55.15 \pm 0.91$ \\
\hline 2 & Saperavi & Temryukskiy & «Busher Vaslin» (France) & $48.50 \pm 0.15$ \\
\hline 3 & Cabernet Sauvignon & Savyanskiy & «Enoventa» (Italy) & $52.35 \pm 0.22$ \\
\hline 4 & Merlot & Gelendzhikskiy & «Diemme» (Italy) & $64.45 \pm 0.34$ \\
\hline 5 & Rebo & Gelendzhikskiy & «Diemme» (Italy) & $64.21 \pm 0.62$ \\
\hline
\end{tabular}

It was shown that the content of organic acids in the pomace ranged from $33 \mathrm{~g} / \mathrm{kg}$ (Saperavi) to $108.2 \mathrm{~g} / \mathrm{kg}$ (Rebo), while the main acid is tartaric, the mass concentration varied from 76.1 (Pinot Noir) to $92.0 \%$ (Rebo) of the total amount of organic acids (Table 2).

Table 2. Content of cations of organic acids, alkali and alkaline-earth metals in grape pomace

\begin{tabular}{|c|c|c|c|c|c|}
\hline \multirow{2}{*}{ Component } & \multicolumn{5}{|c|}{ Mass concentration of ions, g/kg } \\
\cline { 2 - 6 } & Saperavi & $\begin{array}{c}\text { Cabernet } \\
\text { Sauvignon }\end{array}$ & Merlot & Pinot Noir & Rebo \\
\hline Potassium & 1.9 & 8.7 & 17.7 & 5.1 & 18.4 \\
\hline Sodium & 0.8 & 1.3 & 2.2 & 0.8 & 2.1 \\
\hline Magnesium & 0.2 & 0.3 & 0.3 & 0.3 & 0.2 \\
\hline Calcium & 0.3 & 0.7 & 0.7 & 0.6 & 0.7 \\
\hline Wine acid & 27.7 & 27.2 & 45.5 & 86.4 & 100.2 \\
\hline Apple acid & 4.5 & 4.8 & 2.0 & 2.8 & 2.9 \\
\hline succinic acid & 1.8 & 0.2 & 1.8 & 3.1 & 2.5 \\
\hline Lemon acid & 0.9 & 0.7 & 0.7 & 1.3 & 1.0 \\
\hline Lactic acid & 1.6 & 0.6 & & 3.9 & 2.2 \\
\hline
\end{tabular}

Organic acids in pomace are both free and bound with cations of alkali and alkalineearth metals, primarily potassium and calcium. In the studied pomace of grapes, a greater amount of potassium cations was revealed, which is involved in many biochemical reactions that ensure human life [12]. The highest value of the mass concentration of potassium was in pomace from grapes of the Rebo $(18.4 \mathrm{~g} / \mathrm{kg})$ and Merlot $(17.7 \mathrm{~g} / \mathrm{kg})$ varieties of the Gelendzhik region, which confirms early studies on the influence of the place of growing grapes on the cationic composition of pomace [11].

The pomace of red grape varieties is rich in phenolic compounds - the most important biologically valuable components of grapes. They exhibit a wide range of physiological properties - anti-allergenic, anti-inflammatory, antimicrobial, antioxidant, antithrombotic, cardioprotective and vasodilatory effects $[6,7,13-18]$. The following phenolic compounds were identified in the studied pomace of grapes: anthocyanins, flavones, flavan-3-ols, oxycinnamic and hydroxybenzoic acids, procyanidins (Table 3).

Anthocyanins are dyes characteristic of a red color, they are formed during the ripening of the grape berry [13-14]. The main anthocyanins found in grape pomace are the 3-Oglycosides of malvidin, petunidin, cyanidin, peonidin and delphinidin. The highest content of anthocyanins was found in the pomace of Saperavi grapes produced in the Temryuk region, the lowest - in the pomace of grapes from the Merlot variety of the Gelendzhik region. The research results confirm the early obtained data that factors such as the grape variety, its maturity at the time of harvest and processing, weather and climatic conditions have a direct impact on the presence and concentration of these compounds [15-16]. 
Table 3. Composition of phenolic substances in aqueous-alcoholic extracts of grape pomace

\begin{tabular}{|c|c|c|c|c|c|}
\hline \multirow[b]{2}{*}{ Name of polyphenols } & \multicolumn{5}{|c|}{ Mass concentration of polyphenols, $\mathrm{mg} / \mathrm{kg}$} \\
\hline & Saperavi & $\begin{array}{c}\text { Cabernet } \\
\text { Sauvignon }\end{array}$ & Merlot & $\begin{array}{l}\text { Pinot } \\
\text { Noir }\end{array}$ & Rebo \\
\hline \multicolumn{6}{|c|}{ Anthocyanins } \\
\hline Delphinidin-3-O-glycoside & 28 & 24 & 28 & 26 & 31 \\
\hline Cyanidin-3-O-glycoside & 16 & 14 & 10 & 18 & 18 \\
\hline Peonidin-3-O-glycoside & 14 & 12 & 8 & 15 & 12 \\
\hline Petunidin-3-O-glycoside & 2.5 & 2.0 & 0.8 & 3.2 & 2.5 \\
\hline Malvidin-3-O-glycoside & 172 & 144 & 102 & 136 & 147 \\
\hline $\begin{array}{l}\text { Delphinidin-3-O- (6'-acetyl } \\
\text { glycoside) }\end{array}$ & 17 & 12 & 10 & 15 & 17 \\
\hline $\begin{array}{l}\text { Cyanidin-3-O- (6'-acetyl- } \\
\text { glycoside) }\end{array}$ & 2.4 & 1.8 & 0.8 & 1.7 & 1.9 \\
\hline $\begin{array}{l}\text { Peonidin-3-O- (6'-acetyl- } \\
\text { glycoside) }\end{array}$ & 4.7 & 4.2 & 2.8 & 3.1 & 3.6 \\
\hline $\begin{array}{l}\text { Petunidin-3-O- (6'-acetyl- } \\
\text { glycoside) }\end{array}$ & 2.7 & 2.7 & 2.2 & 3.1 & 2.6 \\
\hline $\begin{array}{l}\text { Malvidin-3-O- (6'-acetyl- } \\
\text { glycoside) }\end{array}$ & 3.2 & 2.7 & 1.8 & 2.8 & 3.4 \\
\hline $\begin{array}{l}\text { Delphinidin-3-O- (6'-p- } \\
\text { coumaroyl-glycoside) }\end{array}$ & 2.2 & 1.8 & 1.3 & 2.3 & 2.1 \\
\hline $\begin{array}{l}\text { Petunidin-3-O- (6'-p- } \\
\text { coumaroyl-glycoside) }\end{array}$ & 1.1 & 0.7 & 0.6 & 0.9 & 0.9 \\
\hline $\begin{array}{l}\text { Malvidin -3-O- (6'-p- } \\
\text { coumaroyl glycoside) }\end{array}$ & 3.2 & 3.4 & 2.8 & 2.6 & 3.5 \\
\hline \multicolumn{6}{|c|}{ Flavones } \\
\hline Quercetin & 47 & 45 & 36 & 43 & 51 \\
\hline \multicolumn{6}{|c|}{ Flavan-3-ols } \\
\hline$(+)$ - D-Catechin & 587 & 564 & 522 & 564 & 611 \\
\hline$(-)$ - Epicatechin & 342 & 320 & 308 & 327 & 376 \\
\hline (-) - Epicatechingallate & 10 & 12 & 8 & 8 & 13 \\
\hline \multicolumn{6}{|c|}{ Hydroxycinnamic acids } \\
\hline Caftaric acid & 48 & 44 & 46 & 41 & 52 \\
\hline Cautaric acid & 12 & 17 & 11 & 17 & 16 \\
\hline $\mathrm{n}$-Coumaric acid & 15 & 13 & 11 & 15 & 15 \\
\hline \multicolumn{6}{|c|}{ Hydroxybenzoic acids } \\
\hline Gallic acid & 257 & 233 & 218 & 245 & 154 \\
\hline Lilac acid & 256 & 233 & 198 & 224 & 265 \\
\hline Caffeic acid & 195 & 215 & 159 & 251 & 126 \\
\hline
\end{tabular}

Flavonols are formed by the same biosynthetic pathway as anthocyanins, imparting stability to the color form of anthocyanins, changing or increasing their color intensity [16]. In the studied pomace, they are represented by quercetin, the content of which ranges from 36 (Merlot) to $51 \mathrm{mg} / \mathrm{kg}$ (Rebo).

The pomace phenolic acids are subdivided into oxycinnamic and oxybenzoic acids. The latter are represented by gallic, lilac and caffeic acids. The highest total content of hydroxybenzoic acids was found in the pomace of Pinot Noir and is $720 \mathrm{mg} / \mathrm{kg}$; further, in 
decreasing order of concentration, there are pomaces from Saperavi grape varieties (708 $\mathrm{mg} / \mathrm{kg}$ ), Cabernet Sauvignon (681 mg/kg), Merlot (575 mg/kg) and Rebo (545 mg/kg).

Flavan-3-ols are the most abundant group of flavonoids in the human diet and are readily found in fruits and vegetables [15-17]. They mainly turn into wine from the grape during fermentation. In the studied pomace, they are represented by (+) - D-catechin, (-) epicatechin, (-) - epicatechin gallate. (+) - D-catechin is the most reduced form of grape polyphenols, it has the greatest antioxidant activity. In the studied samples, its content ranges from $522 \mathrm{mg} / \mathrm{kg}$ (Merlot) to $611 \mathrm{mg} / \mathrm{kg}$ (Rebo).

In the studied pomace, vitamins were identified: ascorbic acid, thiamine (B1), riboflavin (B2), nicotinic acid (B3), pantothenic acid (B5), biotin (B7) (Fig. 1).

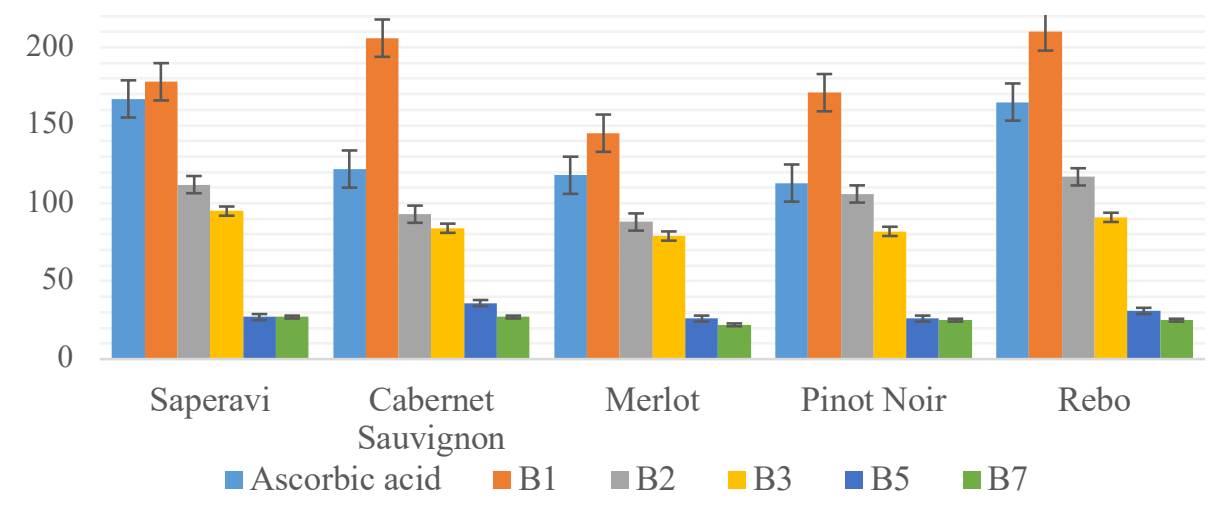

Fig. 1 Mass concentration of vitamins in extracts of the studied pomace of grapes, $\mathrm{mg} / \mathrm{kg}$

The identified vitamins belong to the group of water-soluble vitamins that have a significant effect on human health and play an important role in cellular metabolism [17]. Moreover, in all samples, vitamin B1 prevails over all, then in decreasing order - ascorbic acid, B2, B3, B5, B7. Likewise, depending on the grape variety from which the pomace is obtained, the concentrations of these components differ. The total content of vitamins is the highest in the pomace of Rebo grapes and is $639 \mathrm{mg} / \mathrm{kg}$, the lowest is Merlot (471 $\mathrm{mg} / \mathrm{kg})$.

\section{Conclusion}

It was shown that grape pomace of various grape varieties contain high concentrations of phenolic compounds (including vitamin-like compounds), vitamins and potassium cations. The content of these biologically valuable components in the pomace is directly influenced by the grape variety from which they are obtained, which must be taken into account in the production of biologically active substances that increase the nutritional status of a person.

Acknowledgments. The research was carried out with the financial support of the RFBR and the AKR in the framework of the scientific project No. 19-416-233027 and partly in the framework implementation of FSBSI NCBSSCHVW 


\section{References}

1. T. Ilyas, P. Chowdhary, D. Chaurasia, E. Gnansounou, A. Pandey, P. Chaturvedi, Environ. Technol. Innov., 23, $101592 \quad$ (2021) https://doi.org/10.1016/j.eti.2021.101592

2. Q. Jin, S.F. O'Keefe, A.C. Stewart, A.P. Neilson, Y.T. Kim, H. Huang, Food Bioprod. Process., 127, 139-151 (2021) https://doi.org/10.1016/j.fbp.2021.02.002

3. P. Chowdhary, A. Gupta, E. Gnansounou, A. Pandey, P. Chaturvedi, Environ. Poll., 278, 116796 (2021) https://doi.org/10.1016/j.envpol.2021.116796

4. Y. Martínez-Meza, J. Pérez-Jiménez, N. E. Rocha-Guzmán, M. E. Rodríguez-García, M. Alonzo-Macías, R. Reynoso-Camacho, Food Chem., 360, 130035 (2021) https://doi.org/10.1016/j.foodchem.2021.130035

5. Y. Bao, L. Reddivari, J-Y. Huang, LWT, 133, 109970 (2020) https://doi.org/10.1016/j.lwt.2020.109970

6. I. M. Martins, G. A. Macedo, J. A. Macedo, Food Biosci., 35, 100607 (2020) https://doi.org/10.1016/j.fbio.2020.100607

7. G. Nakov, A. Brandolini, A. Hidalgo, N. Ivanova, V. Stamatovska, I. Dimov, LWT, 134, 109950 (2020) https://doi.org/10.1016/j.lwt.2020.109950

8. B. G. Acan, M. Kilicli, K. Bursa, O. S. Toker, I. Palabiyik, M. Gulcu, M. Yaman, R. Gunes, N. Konar, LWT, 138, $110451 \quad$ (2021) https://doi.org/10.1016/j.lwt.2020.110451

9. M-R. Meini, I. Cabezudo, C. S. Galetto, D. Romanini, Food Biosci., 42, 101168 (2021) https://doi.org/10.1016/j.fbio.2021.101168

10. M. Kuzilov, M. Lozhnikova, M. Zaharova, Yu. Yakuba, Fruit Growing and Viticulture of South Russia, 14, 116-128 (2012) http://journalkubansad.ru/pdf/12/02/13.pdf

11. A.N. Tikhonova, N. M. Ageyeva, S. A. Biryukova, E. V. Globa, A. A. Abakumova Food Processing: Techniques and Technology, 50(3), 493-502 (2020) https://doi.org/10.21603/2074-9414-2020-3-493-502

12. J. Wang, Y. Ma, S. Hou, Biochem. Biophys. Re. Commun., 521, 699-705 (2020) https://doi.org/10.1016/j.bbrc.2019.10.166

13. X. Sui, Y. Zhang, L. Jiang, W. Zhou, In: Encyclopedia of food chemistry, 10-17 (Elsevier, Amsterdam, 2019) https://doi.org/10.1016/B978-0-08-100596-5.21669-7

14. C. Beres, G.N.S. Costa, I. Cabezudo, N.K. da Silva-James, A.S.C. Teles, A.P.G. Cruz, C. Mellinger-Silva, R.V. Tonon, L.M.C. Cabral, S.P. Freitas, Waste Manag., 68, 581594 (2017) https://doi.org/10.1016/j.wasman.2017.07.017

15. V. B. D. Souza, A. Fujita, M. Thomazini, E. R. Da Silva, J. R. Lucon, J. F., M. I. Genovese, C. S. Favaro-Trindade, Food Chem., 164, 380-386 (2014) https://doi.org/10.1016/j.foodchem.2014.05.049

16. H. Xu, X. Liu, Q. Yan, F. Yuan, Y. Gao, Food. Chem., 166. $50-55$ (2015) https://doi.org/10.1016/j.foodchem.2014.05.125

17. R. C. G. Corrêa, J. A. A. Garcia, V. G. Correa, T. F. Vieira, A. Bracht, R. M. Peralta, Adv. Food Nutr. Res., 90, 259-303 (2019) https://doi.org/10.1016/bs.afnr.2019.02.003 